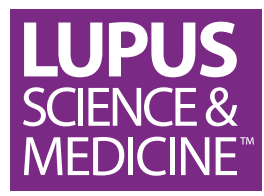

\title{
Differential expression of antibodies to NMDA receptor in anti-NMDA receptor encephalitis and in neuropsychiatric systemic lupus erythematosus
}

\author{
Shunsei Hirohata (1) , 1,2 Keiko Tanaka ${ }^{3}$
}

To cite: Hirohata S, Tanaka K. Differential expression of antibodies to NMDA receptor in anti-NMDA receptor encephalitis and in neuropsychiatric systemic lupus erythematosus. Lupus Science \& Medicine 2019;6:e000359. doi:10.1136/ lupus-2019-000359

Received 28 August 2019 Revised 31 October 2019 Accepted 1 November 2019

Check for updates

(C) Author(s) (or their employer(s)) 2019. Re-use permitted under CC BY-NC. No commercial re-use. See rights and permissions. Published by BMJ.

${ }^{1}$ Rheumatology, Nobuhara Hospital and Institute of Biomechanics, Tatsuno, Hyogo, Japan

${ }^{2}$ Rheumatology and Infectious Diseases, Kitasato University School of Medicine, Sagamihara, Kanagawa, Japan

${ }^{3}$ Animal Model Development, Niigata University Brain Research Institute, Niigata, Japan

Correspondence to Professor Shunsei Hirohata; shunsei@med.kitasato-u.ac.jp

\section{ABSTRACT}

Objective Anti-NMDA receptor encephalitis is the most prevalent autoimmune encephalitis having characteristic clinical features with autoantibodies against tetrameric transmembrane channels composed of combinations of NR1 subunits of NMDA receptors with NR2 subunits, which are detected by cell-based assay (anti-NR1/NR2). On the other hand, antibodies against the linear epitope in NR2 subunit (anti-NR2) have been shown to be expressed in patients with diffuse psychiatric/neuropsychological syndromes of neuropsychiatric SLE (diffuse NPSLE). However, it has not been explored whether anti-NR1/NR2 might be detected in NPSLE, nor has it been clear whether anti-NR2 might have cross-reactivity with anti-NR1/NR2. The current study was therefore performed to explore the prevalence of anti-NR1/NR2 in NPSLE.

Methods Serum specimens were obtained from 31 patients with NPSLE (22 with diffuse NPSLE and 9 with neurological syndromes or polyneuropathy) and from 18 normal healthy subjects. Anti-NR2 and anti-NR1/NR2 were measured by ELISA and cell-based assay, respectively. The positivity for anti-NR2 was defined by a value exceeding mean+2SD of normal healthy subjects.

Results Anti-NR2 was positive in the sera of 19 of 31 patients with NPSLE (in 15 of 22 patients with diffuse NPSLE). By contrast, anti-NR1/NR2 was positive only in 2 of 31 patients with NPSLE (in 2 of 22 patients with diffuse SLE). The positivity for anti-NR1/NR2 was not correlated with anti-NR2 values.

Conclusions These results demonstrate that the prevalence of anti-NR1/NR2 is extremely low in NPSLE. Moreover, the data also confirm that anti-NR2 antibodies do not have cross-reactivity with anti-NR1/NR2.

\section{INTRODUCTION}

Neuropsychiatric manifestations in SLE are difficult complications that may cause substantial impairment of quality of life as well as disability. ${ }^{12}$ Previous studies demonstrated that IgG antineuronal antibodies (anti-N) were specifically elevated in the cerebrospinal fluid (CSF) of patients with active neuropsychiatric SLE (NPSLE), ${ }^{3}{ }^{4}$ whereas the targets of these anti-N remained unclear for a long time. Of note, it was demonstrated that a subset of murine anti-DNA antibodies crossreacted with a sequence within the $\mathrm{N}$-methylD-aspartate (NMDA) receptor subunit NR2. ${ }^{56}$ More importantly, recent studies have demonstrated that CSF anti-NMDA receptor NR2 antibodies (anti-NR2) are associated with diffuse psychiatric/neuropsychological syndromes of human NPSLE. ${ }^{7-9}$

On the other hand, a new category of encephalitis has been discovered in patients with ovarian teratoma, characterised by the sequential development of prodromal symptoms, prominent psychiatric manifestations, and seizures followed by catatonia, hypoventilation and involuntary orofacial-limb movements. ${ }^{10-14}$ This autoimmune encephalitis has been found to be closely related to the antibodies against tetramerised NR1-NR2 subunits of NMDA receptors detected by cellbased assay (anti-NR1/NR2) mainly in CSF. ${ }^{15}$ Thus, it has been called anti-NMDA receptor encephalitis. $^{15}$

Since there is a close analogy of clinical characteristics between diffuse NPSLE and anti-NMDA receptor encephalitis, it is possible that a fraction of patients with diffuse NPSLE might express anti-NR1/NR2. However, it has not been explored whether anti-NR1/NR2 might be expressed in NPSLE, nor has it been clear whether anti-NR2 might have crossreactivity with anti-NR1/NR2. The current study was therefore performed to explore the prevalence of anti-NR1/NR2 in NPSLE.

\section{METHODS}

\section{Patients and samples}

Thirty-one patients with SLE were included in the present study. All patients fulfilled the American College of Rheumatology (ACR) 1982 revised criteria for the classification of SLE. ${ }^{16}$ Of the 31 patients with SLE, 22 showed diffuse psychiatric/neuropsychological syndromes (diffuse NPSLE) according to 


\begin{tabular}{lc}
\hline Table 1 Profiles of the patients studied & \\
\hline Patients with SLE & 31 \\
Diffuse NPSLE & 22 \\
Acute confusional state & 17 \\
Anxiety disorder & 1 \\
Cognitive dysfunction & 1 \\
Mood disorder & 0 \\
Psychosis & 3 \\
Focal NPSLE & 9 \\
Cerebrovascular disease & 1 \\
Demyelinating syndrome & 1 \\
Headache & 1 \\
Seizure disorder & 5 \\
Polyneuropathy & 1 \\
Non-SLE control patients & 18 \\
\hline
\end{tabular}

NPSLE, neuropsychiatric SLE.

the 1999 ACR definition of NPSLE, ${ }^{17}$ whereas 9 patients showed neuropsychiatric manifestations other than diffuse NPSLE, including neurological syndromes and peripheral nervous system involvement (focal NPSLE) (table 1). Among the 22 patients with diffuse NPSLE, 17 were complicated with acute confusional state, the most severe form of diffuse NPSLE. ${ }^{17}$ In addition, serum samples from 18 normal healthy individuals were studied. CSF specimens were obtained from patients by lumbar puncture on the same day serum samples were obtained, when the diagnosis of NPSLE was made by neurologists and rheumatologists. These samples were kept frozen at $-30^{\circ} \mathrm{C}$ until they were assayed. All assays were performed without knowledge of the diagnosis or clinical presentations. Furthermore, on entering the present study, the diagnosis of 31 patients with NPSLE and its classification was reconfirmed by hospital case records.

\section{Measurement of autoantibodies to the NMDA receptor subunit NR2}

Anti-NR2 in sera and CSF was determined by specific ELISA using the highly purified synthetic 10 amino-acid peptide DWEYSVWLSN, ${ }^{57}$ conjugated to human serum albumin (HSA) as previously described. ${ }^{78}$ The concentration of anti-NR2 that produced half of the maximal absorbance at $492 \mathrm{~nm}$, given by saturating concentrations of anti-NR2 in the ELISA plate, was arbitrarily defined as $1 \mathrm{U} / \mathrm{mL}$. The specific anti-NR2 activities were determined by subtracting the values for the non-specific binding activity to HSA from those for binding activity to NR2 peptide-HSA conjugates. $^{78}$

\section{Cell-based assay for anti-NR1/NR2}

Human embryonic kidney (HEK) 293 cells cotransfected with plasmid DNAs encoding the NMDA receptor subunits NR1 and NR2B, which will express on the cell surface as a tetrameric form of receptor, as previously described. ${ }^{18-20}$ At 12 hours after transfection, HEK cells were fixed in $4 \%$ paraformaldehyde in $0.1 \mathrm{M}$ phosphatebuffered saline (PBS, pH 7.4) for $20 \mathrm{~min}$. Non-specific binding was blocked with $10 \%$ goat serum/PBS, and cells were incubated with patients' sera (1:10-400) or CSF (1:2) in $0.02 \%$ Triton X-100 and $10 \%$ goat serum in PBS overnight at $4^{\circ} \mathrm{C}$ and then with fluorescein isothiocyanateconjugated antihuman IgG (Dako, Glostrup, Denmark; 1:50) for 1 hour. SlowFade Gold antifade reagent (Invitrogen Japan, Tokyo) was then applied to the slides, and staining was observed under a fluorescence microscope (AxioVision, Zeiss) in a dark room by trained technologists who were not aware of the diagnosis of patients. First screening was performed with sera at 1:10 or CSF at 1:2 in reference to negative and positive controls. The negative control may not appear completely dark, but will often display low-level non-specific fluorescence, whereas the positive control will display bright green fluorescence (figure 1A). When the fluorescence was judged stronger compared with negative control, serial dilutions were used for determining antibody titres, as is used for detection of ANA. ${ }^{21}$ Thus, final dilutions that resulted in the fluorescence equal to that of negative control were reported as titres of the samples.

We further compared the staining pattern of HEK 293 cells cotransfected with plasmid DNAs encoding the NMDA receptor subunits NR1 and NR2B by CSF samples from three patients with anti-NMDA receptor encephalitis and those from two patients with anti-NMDA receptor unrelated encephalitis. As shown in figure 1B, all the three CSF samples from patients with ant-NMDA receptor encephalitis displayed bright green fluorescence, whereas two CSF samples from anti-NMDA receptor encephalitis resulted in only low-level non-specific fluorescence or dark staining. These results confirm that the cell-based assay is sensitive enough to detect anti-NR1/NR2 in patients with anti-NMDA receptor encephalitis.

\section{Measurement of antiribosomal P}

It has been found that antiribosomal $\mathrm{P}$ antibodies bind neuronal cells and one of the major constituents of anti$\mathrm{N}^{22}$ Thus, in order to examine the relationship of antiribosomal $\mathrm{P}$ and anti-NR1/NR2, serum antiribosomal $\mathrm{P}$ was determined by ELISA using purified bovine ribosomal $\mathrm{P}$ proteins (Arotec, Wellington, New Zealand), as previously described. ${ }^{22}$

\section{Statistical analysis}

Comparisons among the three groups were carried out by Kruskal-Wallis test with Dunn's multiple comparison test, using GraphPad Prism 4 for Windows V.4.03 (GraphPad Software, San Diego, California).

\section{RESULTS}

Initial experiments compared the serum levels of antiNR2 in diffuse NPSLE, focal NPSLE and non-SLE control. As shown in figure 2, serum anti-NR2 levels were significantly elevated in diffuse NPSLE $(p<0.0001)$ and 
A

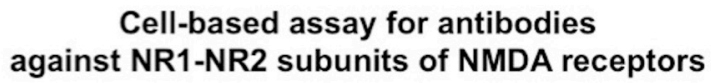

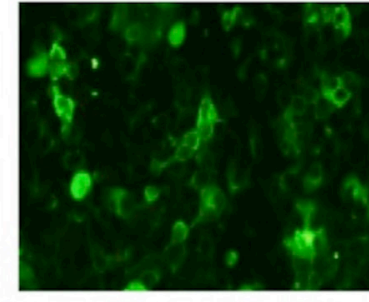

Positive control $\mathrm{CSF} \times 2$

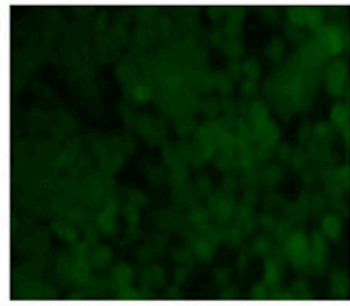

Negative control CSF $\times 2$
B

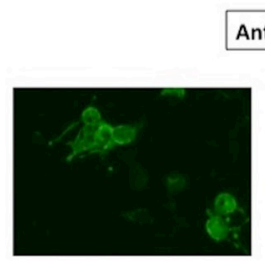

$38 y /$ female
Anti-NMDA receptor encephalitis

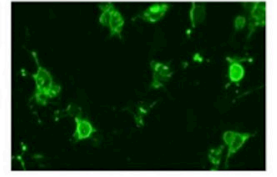

19y/female

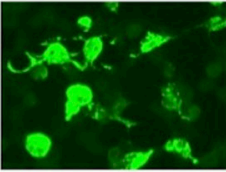

$28 y / f e m a l e$

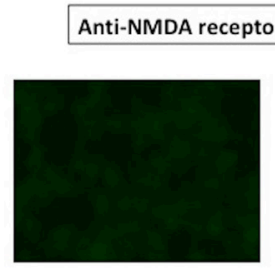

$8 y /$ female

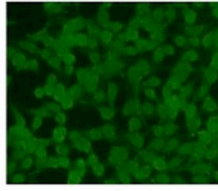

$32 y / f e m a l e$
Figure 1 Cell-based assay of antibodies against NR1-NR2 subunits of NMDA receptors. (A) HEK 293 cells transfected with plasmid DNAs encoding the NMDA receptor subunits NR1 and NR2B with cell membrane coexpression were reacted with patients' CSF samples positive or negative anti-NR1/NR2 (diluted by 1:2) from patients with anti-NMDA receptor encephalitis or with anti-NMDA receptor unrelated encephalitis, respectively, followed by detection with fluorescein isothiocyanate-conjugated anti-human IgG. (B) Comparison of patients with anti-NMDA receptor encephalitis and those with anti-NMDA receptor unrelated encephalitis is shown. CSF samples (diluted by 1:2) from three patients with anti-NMDA receptor encephalitis or from two patients with anti-NMDA receptor unrelated encephalitis, respectively, were assayed for anti-NR1/NR2, as described above. CSF, cerebrospinal fluid; HEK, human embryonic kidney; NMDA, $\mathrm{N}$-methyl-D-aspartate.

in focal NPSLE ( $\mathrm{p}=0.0079$ ) compared with those in nonSLE control. Serum antiribosomal $P$ levels were significantly elevated in diffuse NPSLE $(p=0.0093)$ but not in focal NPSLE $(p=0.1204)$ compared with those in non-SLE control. Serum anti-NR2 and antiribosomal P appeared to be higher in diffuse NPSLE than in focal NPSLE, although it did not reach statistical significance.

When the upper limit of normal value for the serum anti-NR2 was set as the mean+2 SD $(43.4 \mathrm{U} / \mathrm{mL})$ of nonSLE control, anti-NR2 was positive in 19 of 31 patients with NPSLE (in 15 of 22 patients with diffuse NPSLE and
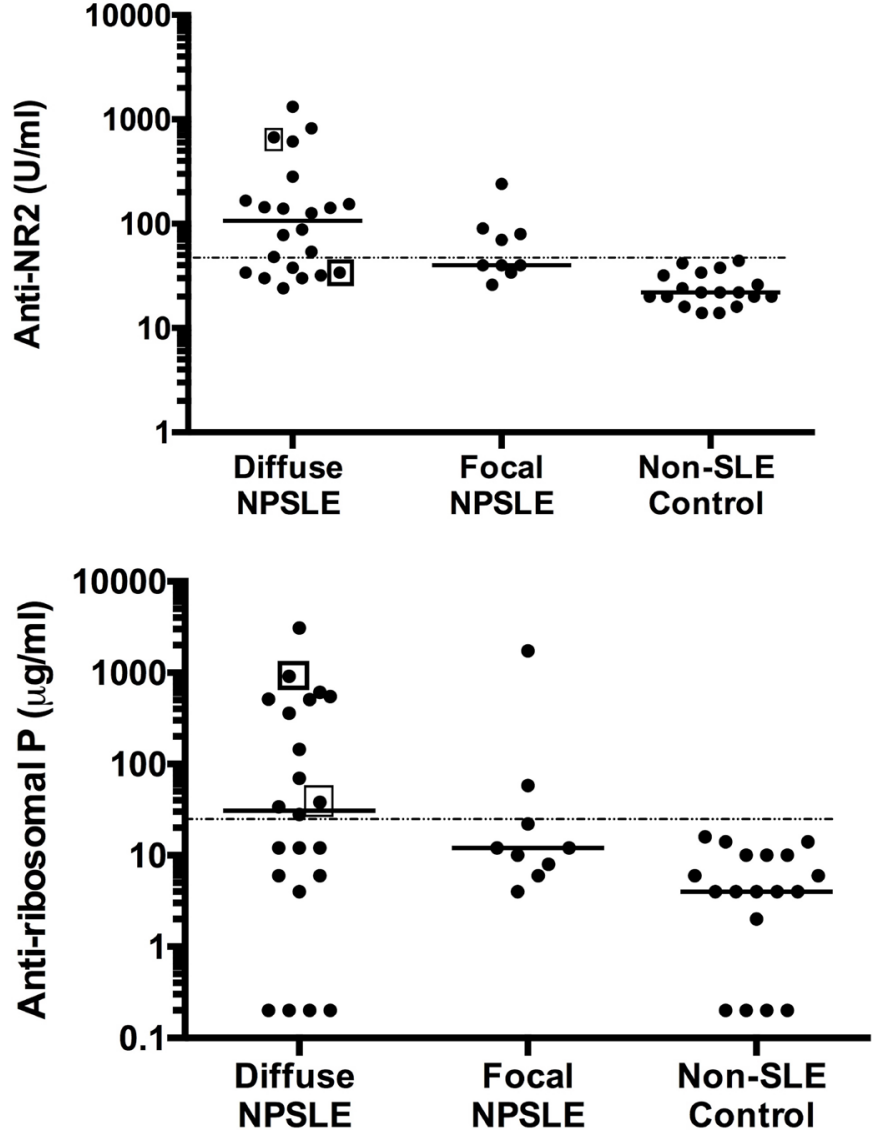

Figure 2 Serum anti-NR2 and antiribosomal $P$ in diffuse NPSLE, focal NPSLE and non-SLE control. Median values are shown by horizontal lines. Points in square are samples positive for anti-NR1/NR2 by cell-based assay. The cut-off lines (mean+2SD of values for healthy control) are indicated by dotted lines. NPSLE, neuropsychiatric SLE.

in 4 of 9 patients with focal NPSLE) (table 2), whereas none of the 18 healthy control subjects exceeded the upper limit. Moreover, with the upper limit of normal value for the serum antiribosomal $\mathrm{P}$ set as the mean+2 SD $(32.1 \mu \mathrm{g} / \mathrm{mL})$ of non-SLE control, serum antiribosomal $\mathrm{P}$ was positive in 13 of 31 patients with NPSLE (in 11 of 22 patients with diffuse NPSLE and in 2 of 9 patients with focal NPSLE). These results are consistent with previous reports that disclosed the high prevalence of anti-NR2 and antiribosomal $\mathrm{P}$ in sera from patients with NPSLE, especially diffuse NPSLE. ${ }^{4} 22$

As for serum anti-NR1/NR2, only two patients with diffuse NPSLE, but none of nine patients with focal NPSLE, showed positive results. Thus, serum samples from patients 10 and 20 showed bright green fluorescence, whereas serum samples from three patients (patients 2, 12 and 17 in table 2) who showed high antiNR2 displayed only low-level non-specific fluorescence or dark staining (figure 3 ). The remaining 26 serum samples showed similar staining patterns as those of sera from patients 2, 12 and 17 (data not shown). The positivity of anti-NR1/NR2 was not correlated with the positivity of serum anti-NR2 or with that of serum antiribosomal 


\begin{tabular}{|c|c|c|c|c|c|}
\hline $\begin{array}{l}\text { Patient } \\
\text { number }\end{array}$ & Age and gender & Diagnosis & Anti-NR2 & Antiribosomal P & Anti-NR1/NR2 \\
\hline 1 & $50 \mathrm{~F}$ & ACS & 154 & 12 & - (negative) \\
\hline 2 & $53 \mathrm{~F}$ & ACS & 824 & 38 & - \\
\hline 3 & $33 \mathrm{~F}$ & ACS & 38 & 0 & - \\
\hline 4 & $28 \mathrm{M}$ & ACS & 30 & 144 & - \\
\hline 5 & $23 \mathrm{~F}$ & ACS & 24 & 550 & - \\
\hline 6 & $14 \mathrm{~F}$ & ACS & 284 & 512 & - \\
\hline 7 & $66 \mathrm{~F}$ & ACS & 54 & 3094 & - \\
\hline 8 & $39 \mathrm{M}$ & ACS & 88 & 4 & - \\
\hline 9 & $51 \mathrm{~F}$ & ACS & 34 & 12 & - \\
\hline 10 & $65 \mathrm{~F}$ & ACS & 34 & 916 & 1:40 (positive) \\
\hline 11 & $32 \mathrm{~F}$ & ACS & 32 & 12 & - \\
\hline 12 & $46 \mathrm{~F}$ & ACS & 1320 & 0 & - \\
\hline 13 & $30 \mathrm{~F}$ & ACS+myelitis & 142 & 0 & - \\
\hline 14 & $34 \mathrm{~F}$ & ACS & 166 & 508 & - \\
\hline 15 & $19 \mathrm{~F}$ & ACS & 144 & 28 & - \\
\hline 16 & $42 \mathrm{~F}$ & ACS+myelitis & 140 & 0 & - \\
\hline 17 & $37 \mathrm{~F}$ & ACS & 616 & 360 & - \\
\hline 18 & $39 \mathrm{~F}$ & Anx & 30 & 6 & - \\
\hline 19 & $65 \mathrm{~F}$ & Cog & 78 & 6 & - \\
\hline 20 & $43 \mathrm{~F}$ & Psy & 672 & 34 & 1:80 (positive) \\
\hline 21 & $37 \mathrm{~F}$ & Psy & 48 & 70 & - \\
\hline 22 & $17 \mathrm{~F}$ & Psy & 126 & 612 & - \\
\hline 23 & $71 \mathrm{~F}$ & Seizure & 240 & 58 & - \\
\hline 24 & $22 \mathrm{~F}$ & Seizure & 70 & 6 & - \\
\hline 25 & $40 \mathrm{~F}$ & Seizure & 40 & 12 & - \\
\hline 26 & $33 \mathrm{~F}$ & Demyelinating & 34 & 4 & - \\
\hline 27 & $42 \mathrm{~F}$ & CVD & 40 & 8 & - \\
\hline 28 & $44 \mathrm{~F}$ & Seizure & 90 & 12 & - \\
\hline 29 & $60 \mathrm{~F}$ & Seizure & 40 & 1728 & - \\
\hline 30 & $32 \mathrm{~F}$ & Peripheral & 80 & 22 & - \\
\hline 31 & $39 \mathrm{~F}$ & Headache & 26 & 10 & - \\
\hline
\end{tabular}

Patients 1-22: diffuse NPSLE.

Patients 23-31: focal NPSLE.

Bold figures denote positive results for anti-NR2 and antiribosomal P by ELISA.

ACS, acute confusional state; anx, anxiety disorder; Cog, cognitive dysfunction; CVD, cerebrovascular disease.; F, female; M, male; psy, psychosis.

$\mathrm{P}$ (table 2). These results indicate that the expression of anti-NR1/NR2 is extremely rare in NPSLE. Moreover, the data have also disclosed that anti-NR1/NR2 antibodies do not cross-react with anti-NR2. Finally, anti-NR1/NR2 was not detected in CSF from the two patients whose sera were positive for anti-NR1/NR2.

\section{DISCUSSION}

The results in the present study have demonstrated for the first time that the expression of anti-NRI/NR2,
anti-NMDA receptor antibodies detected by cell-based assay, is extremely rare in serum or CSF from patients with diffuse NPSLE or focal NPSLE. It has been revealed that the epitope of anti-NR2 is directed to the linear aminoacid sequence shared by NR2A and NR2B subunits. ${ }^{5}$ It was thus possible that anti-NR2 might react with HEK 293 cells transfected with plasmid DNAs encoding NR1 and NR2B. However, nearly all the sera from patients with positive serum anti-NR2 showed no binding to HEK 293 cells cotransfected with plasmid DNAs encoding NR1 and 


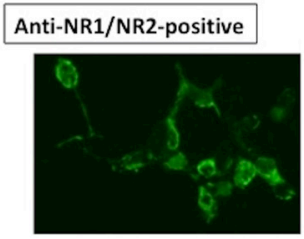

No.10

Anti-NR1/NR2-negative

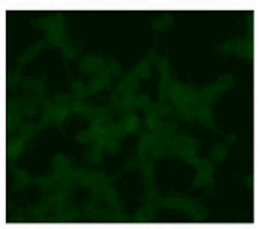

No.2

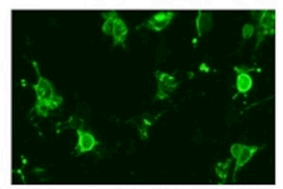

No. 20

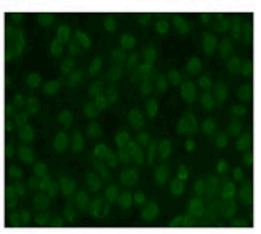

No.12

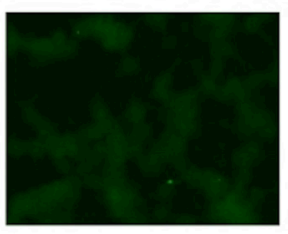

No.17
Figure 3 Comparison of serum cell based-assay for patients with NPSLE with positive anti-NR1/NR2 and those with negative anti-NR1/NR2. Stainings of HEK 293 cells transfected with plasmid DNAs encoding the NMDA receptor subunits NR1 and NR2B by serum samples (diluted by 1:10) from two patients with positive anti-NR1/NR2 (patients 10 and 20 in table 2) or from three patients with negative antiNR1/NR2 (patients 2, 12 and 17 in table 2) who showed high anti-NR2 are shown. HEK, human embryonic kidney; NMDA, $\mathrm{N}$-methyl-D-aspartate; NPSLE, neuropsychiatric SLE.

NR2B. ${ }^{18}$ It is therefore suggested that the linear epitope of anti-NR2 might be sterically located on the transfected HEK 293 cells so that anti-NR2 might not access.

The critical epitope of anti-NR1/NR2 antibodies has been considered to be located in the extracellular N-terminal domain of the NR1 subunit. ${ }^{15}$ Thus, the deletion of amino-acid residues 25-380 in NR1 subunit markedly decreased the reactivity of anti-NR1/NR2 to the transfectants despite the successful expression of deficient NR1 and NR2B subunit on their surface. ${ }^{15}$ It has been disclosed that anti-NR1/NR2 decreased the numbers of cell-surface NMDA receptors and NMDA receptor clusters in postsynaptic dendrites in a reversible fashion, but did not induce apoptosis of neurons. ${ }^{15}$ By contrast, it has been shown that anti-NR2 induced apoptosis of neurons when they were injected into the brain of mice. ${ }^{5}$ In this regard, it is likely that signals delivered through the NR1 subunit might result in different biological effects on neurons from those delivered through the NR2 subunit of NMDA receptor, although further studies are required to confirm this point.

Anti-NMDA receptor encephalitis was most frequently associated with ovarian teratoma among neoplasms. ${ }^{10-15}$ Moreover, the resection of tumours usually facilitated the amelioration of the manifestation in anti-NMDA receptor encephalitis. ${ }^{15}$ It is therefore likely that antigenspecific immune responses to some specific antigens included in the ovarian teratoma might be responsible for the expression of anti-NR1/NR2 antibodies. In fact, it has been demonstrated that tissues in ovarian teratoma contain NMDA receptors. ${ }^{23}$ Moreover, histological analysis of ovarian teratoma has revealed that lymphocyte infiltration was more frequent in patients with encephalitis compared with non-encephalitis patients, suggesting the presence of antigen-driven immune responses.

Although the mechanism of the expression of a variety of autoantibodies in SLE remains unclear, it is not assumed as a simple antigen-specific immune response. ${ }^{24}$ Thus, in addition to antigen-driven responses, several mechanisms have been suggested, including polyclonal B cell activation, impaired apoptotic pathways or the outcome of idiotypic network dysregulation. ${ }^{24}$ Notably, the expression of anti-NR2 antibodies was correlated with the expression of anti-Sm antibodies along with the increasing activity of NPSLE. ${ }^{25}$ Thus, the positive correlation between these two autoantibodies strongly suggests the presence of abnormal responses other than antigenspecific reactions. In this regard, the mechanism of the expression of anti-NR2 is likely to be different from that of anti-NR1/NR2.

It should be pointed out that anti-NR1/NR2 was not detected in CSF from the two patients whose sera were positive for anti-NR1/NR2 in the present study. Since the presence of anti-NR1/NR2 in CSF is crucial to the development of anti-NMDAR encephalitis, ${ }^{15}$ it is suggested that anti-NR1/NR2 might not play any significant role in the development of neuropsychiatric manifestations even in these two patients with NPSLE. Thus, this type of encephalitis is considered to be extremely rare in SLE.

Contributors SH had full access to all of the data in the study and takes responsibility for the decision to submit for publication. SH designed the study and participated in experimental procedures, data collection, data analysis, data interpretation, and manuscript drafting and critical revising. KT contributed to data collection, data analysis, data interpretation, and manuscript drafting and critical revising. SH and KT agreed to be accountable for all aspects of the work in ensuring that questions related to the accuracy or integrity of any part of the work are appropriately investigated and resolved. Both authors read and approved the final version of the manuscript to be published.

Funding This work was supported by grant-in-aid (c) from the Ministry of Education, Culture, Sports, Science and Technology of Japan (no 15K09556) and by a grant from Japan Agency for Medical Research and Development (no 15eK0410022h0001).

Competing interests None declared.

Patient consent for publication Not required.

Ethics approval All the 49 individuals gave informed consent. This study was approved by the institutional ethical committee of Kitasato University School of Medicine (ref no B09-55).

Provenance and peer review Not commissioned; externally peer reviewed. Data availability statement All data relevant to the study are included in the article.

Open access This is an open access article distributed in accordance with the Creative Commons Attribution Non Commercial (CC BY-NC 4.0) license, which permits others to distribute, remix, adapt, build upon this work non-commercially, and license their derivative works on different terms, provided the original work is properly cited, appropriate credit is given, any changes made indicated, and the use is non-commercial. See: http://creativecommons.org/licenses/by-nc/4.0/.

ORCID iD

Shunsei Hirohata http://orcid.org/0000-0003-1911-7383

\section{REFERENCES}

1 Gibson T, Myers AR. Nervous system involvement in systemic lupus erythematosus. Ann Rheum Dis 1975;35:398-406. 
2 Harris EN, Hughes GR. Cerebral disease in systemic lupus erythematosus. Springer Semin Immunopathol 1985;8:251-66.

3 Bluestein HG, Williams GW, Steinberg AD. Cerebrospinal fluid antibodies to neuronal cells: association with neuropsychiatric manifestations of systemic lupus erythematosus. Am J Med 1981;70:240-6.

4 Isshi K, Hirohata S. Differential roles of the anti-ribosomal P antibody and antineuronal antibody in the pathogenesis of central nervous system involvement in systemic lupus erythematosus. Arthritis Rheum 1998;41:1819-27.

5 DeGiorgio LA, Konstantinov KN, Lee SC, et al. A subset of lupus anti-DNA antibodies cross-reacts with the NR2 glutamate receptor in systemic lupus erythematosus. Nat Med 2001;7:1189-93.

6 Kowal C, DeGiorgio LA, Nakaoka T, et al. Cognition and immunity; antibody impairs memory. Immunity 2004;21:179-88.

7 Arinuma Y, Yanagida T, Hirohata S. Association of cerebrospinal fluid anti-NR2 glutamate receptor antibodies with diffuse neuropsychiatric systemic lupus erythematosus. Arthritis Rheum 2008;58:1130-5.

8. Hirohata S, Arinuma Y, Yanagida T, et al. Blood-Brain barrier damages and intrathecal synthesis of anti-N-methyl-D-aspartate receptor NR2 antibodies in diffuse psychiatric/neuropsychological syndromes in systemic lupus erythematosus. Arthritis Res Ther 2014;16:R77.

9 Mader S, Jeganathan V, Arinuma Y, et al. Understanding the antibody repertoire in neuropsychiatric systemic lupus erythematosus and neuromyelitis optica spectrum disorder: do they share common targets? Arthritis Rheumatol 2018;70:277-86.

10 Dalmau J, Tüzün E, Wu H-yan, et al. Paraneoplastic anti-N-methyl$\mathrm{D}$-aspartate receptor encephalitis associated with ovarian teratoma. Ann Neurol 2007;61:25-36.

11 Sansing LH, Tüzün E, Ko MW, et al. A patient with encephalitis associated with NMDA receptor antibodies. Nat Clin Pract Neurol 2007;3:291-6.

12 Kataoka H, Dalmau J, Ueno S. Paraneoplastic encephalitis associated with ovarian teratoma and N-methyl-D-aspartate receptor antibodies. Eur J Neurol 2008;15:e5-6.

13 lizuka T, Sakai F, Ide T, et al. Anti-Nmda receptor encephalitis in Japan: long-term outcome without tumor removal. Neurology 2008;70:504-11.
14 Seki M, Suzuki S, lizuka T, et al. Neurological response to early removal of ovarian teratoma in anti-NMDAR encephalitis. J Neurol Neurosurg Psychiatry 2008;79:324-6.

15 Dalmau J, Gleichman AJ, Hughes EG, et al. Anti-Nmda-Receptor encephalitis: case series and analysis of the effects of antibodies. Lancet Neurol 2008;7:1091-8.

16 Tan EM, Cohen AS, Fries JF, et al. The 1982 revised criteria for the classification of systemic lupus erythematosus. Arthritis Rheum 1982;25:1271-7.

17 ACR AD hoc Committee on neuropsychiatric lupus nomenclature: the American College of rheumatology Nomenclature and case definitions for neuropsychiatric lupus syndromes. Arthritis Rheum 1999;42:599-608.

18 Zhang Q, Tanaka K, Sun P, et al. Suppression of synaptic plasticity by cerebrospinal fluid from anti-NMDA receptor encephalitis patients. Neurobiol Dis 2012;45:610-5.

19 Takano S, Takahashi Y, Kishi H, et al. Detection of autoantibody against extracellular epitopes of N-methyl-D-aspartate receptor by cell-based assay. Neurosci Res 2011;71:294-302.

20 Ando Y, Shimazaki H, Shiota K, et al. Prevalence of elevated serum anti-N-methyl-D-aspartate receptor antibody titers in patients presenting exclusively with psychiatric symptoms: a comparative follow-up study. BMC Psychiatry 2016;16:226.

21 Buchner C, Bryant C, Eslami A, et al. Anti-Nuclear antibody screening using HEp-2 cells. J Vis Exp 2014;88:e51211.

22. Hirohata S, Arinuma $Y$, Takayama M, et al. Association of cerebrospinal fluid anti-ribosomal $P$ protein antibodies with diffuse psychiatric/neuropsychological syndromes in systemic lupus erythematosus. Arthritis Res Ther 2007:9:R44.

23 Tabata E, Masuda M, Eriguchi M, et al. Immunopathological significance of ovarian teratoma in patients with anti-N-methyl-daspartate receptor encephalitis. Eur Neurol 2014;71:42-8.

24 Sherer Y, Gorstein A, Fritzler MJ, et al. Autoantibody explosion in systemic lupus erythematosus: more than 100 different antibodies found in SLE patients. Semin Arthritis Rheum 2004;34:501-37.

25. Hirohata S, Sakuma Y, Yanagida T, et al. Association of cerebrospinal fluid anti-Sm antibodies with acute confusional state in systemic lupus erythematosus. Arthritis Res Ther 2014;16:450. 